\title{
Distributive Justice and Beneficence
}

\section{I Introduction}

Justice is a matter of giving individuals what they are due. Four broad concepts of justice can be distinguished. Retributive justice gives people what they are due - for example, punishment - in virtue of their wrongful acts. Restorative justice gives people what they are due - for example, compensation - in virtue of past wrongs they experienced. Distributive justice gives people what they are due independent of past wrongful actions. It includes the distribution of valuable resources (such as medical care and job opportunities), the distribution of burdens (such as taxation and jury duty), and the assignment and enforcement of certain legal rights (such as regarding marriage and inheritance). Finally, in contrast to these concepts of substantive justice, there is also procedural justice, which concerns the fairness of the processes by which decisions regarding matters of substantive justice are made. Our main interest here is in distributive justice, though, as will become clear, restorative justice may also be relevant to some of the applications of our views on distributive justice.

Beneficence concerns our duties to benefit other individuals. Being benefited is the converse of being harmed: someone is benefited when they are made better off than they would have been otherwise (Chapter 4). We can distinguish three types of duties of beneficence. The imperfect duty of beneficence is a duty to contribute substantially, relative to one's ability, to assist individuals in need over the course of one's life. Individual agents have discretion over exactly how and when this duty is discharged. The perfect duty of beneficence or duty of rescue is a duty that all agents have to provide large benefits to others when they can do so at a sufficiently low cost to themselves. Finally, there are special duties of beneficence that attach to agents in virtue of their relationships and the roles they occupy, such as the special duties of parents to their children or of clinicians to their patients. 
At first blush, it might seem peculiar that we treat distributive justice and beneficence together. Although each addresses the provision of benefits and burdens, in the bioethics literature they are usually treated as distinct. ${ }^{\mathrm{I}}$ For the purpose of answering certain, limited questions relating to clinical care and research we agree that it can be helpful to separate them. However, as the following discussion reveals, we think that the content of one depends on the content of the other.

This chapter divides the theoretical landscape in two ways: (I) between the ideal and the nonideal and (2) between how institutions should be arranged and how individuals should behave. The distinction between ideal and nonideal theory comes from political philosophy. ${ }^{2}$ Ideal theory concerns how just social and international institutions should be organized and how individuals ought to act against a background of just institutions and on the assumption that other people will act as they should. Nonideal theory concerns what ought to be done when the institutional background is unjust and other people cannot be relied upon to act well. More specifically, we take nonideal theory to address what particular individual actors - including states and persons - should do in the world as it is now.

Regarding institutions, domestically, we defend a relatively generic liberal egalitarian view about distributive justice according to which unchosen differences in individual advantage within a society are prima facie unjust. ${ }^{3}$ Plausible justifications for differences in individual advantage include that the benefits to other parties of inequality are sufficiently large, that the inequality is necessary to secure a fundamental right, or that the inequality results from voluntary, informed decisions by the disadvantaged parties. Globally, the reasons that lead us to endorse liberal egalitarianism also lead us to endorse a form of cosmopolitanism. According to this view, similar principles of justice apply internationally as apply domestically. For individuals, we argue for extensive duties of beneficence, albeit consistent with considerable leeway for people to prioritize their own projects.

In our nonideal world these conclusions have far-reaching consequences for the setup of institutions and the actions of individuals. We show how they imply that national governments should ensure that all their residents have access to affordable health care and how they give us

I See, e.g., Tom Beauchamp and James Childress. Principles of Biomedical Ethics, 7th ed. (New York: Oxford University Press, 2013).

2 See, e.g., John Rawls, $A$ Theory of Justice (Cambridge, MA: Harvard University Press, I97I), 35 I.

3 We borrow this notion from Douglas MacKay, who articulates a form of "generic liberalism" ("Standard of Care, Institutional Obligations, and Distributive Justice," Bioethics 29 [2015]: $262-273$, at 264). 
reasons to amend the global intellectual property regime that governs pharmaceutical patents.

\subsection{Just Institutions}

\section{A Defense of Liberal Egalitarianism}

Social institutions - understood broadly to include legal regimes, as well as government bodies and their characteristic activities - are a source of tremendous benefits. The particular ways in which they distribute benefits require justification. For example, property laws convey benefits by facilitating economic transactions that are beneficial to the parties transacting. Specific property laws stand in need of justification since what counts as property and how it is obtained affect who benefits and how much from these transactions. Likewise, health care funded through general taxation provides benefits to patients in the form of better health and financial risk protection. Government-funded health care stands in need of justification since it involves distributing resources that would otherwise belong to the general population to patients and health care providers. We take it that the way in which social institutions distribute resources, rights, opportunities, and so on is just if it could be justified to each person affected by those institutions. We submit that social institutions that are consistent with liberal egalitarianism can be justified in this way.

Egalitarians like us regard it as presumptively unjust if one person is worse off than another person as a result of factors beyond their control. ${ }^{4}$ All else being equal, such a difference should be prevented if possible. This rules out treating people differently on the basis of morally irrelevant features, such as race or sexual orientation. ${ }^{5}$ However, it does not mean that people should always be treated the same. Most obviously, people have different needs. If we want to give them equal opportunities to

${ }^{4}$ We therefore approach distributive justice through the lens of "luck egalitarianism." This view may be contrasted with "social egalitarianism," which bases concerns of justice in the value of individuals being able to participate as free and equal citizens in their society (see Alex Voorhoeve, "Why HealthRelated Inequalities Matter and Which Ones Do," in Ole Norheim, Ezekiel Emanuel, and Joseph Millum [eds.], Global Health Priority-Setting [New York: Oxford University Press, 2019], I45-I6I). For an early representative of an implicitly luck egalitarianism approach in bioethics, see Robert Veatch, A Theory of Medical Ethics (New York: Basic Books, I98I).

5 We regard these as good examples of morally irrelevant features in the ideal case (that is, the case where institutions are just and individuals act justly). It does not follow that they are morally irrelevant in the nonideal (actual) case. For example, it might be justified to give preferential treatment in hiring to members of a racial group that has historically been discriminated against. 
flourish, then they may need to be given unequal amounts of resources. ${ }^{6}$ For example, someone who is near-sighted and someone with $20 / 20$ vision differ in their need for corrective lenses. It is consistent with egalitarianism to supply only the former with glasses.

There may be reasons for treating people in ways that lead to unchosen inequalities in well-being. One prominent reason is that allowing some inequalities may substantially increase the total resources that are available for distribution and so increase the total well-being of a society. For example, allowing variation in wages plausibly incentivizes individuals to work more, to invest in economically productive skills, and to pursue careers for which there is high demand. Under the right conditions, this increases net economic productivity.

Egalitarians disagree about when these unchosen inequalities in outcomes are consistent with treating everyone as an equal. ${ }^{7}$ Rawls, for example, defends the difference principle, according to which inequalities are permissible only when they most benefit the least well-off:

No one deserves his greater natural capacity nor merits a more favorable starting place in society. But, of course, this is no reason to ignore, much less to eliminate these distinctions. Instead, the basic structure can be arranged so that these contingencies work for the good of the least fortunate. ${ }^{8}$

Rawls restricted the scope of his theory of justice to representative persons holding different social positions and set aside any special problems raised by those in need of health care. ${ }^{9}$ But consideration of cases other than healthy workers in the paid economy is necessary for thinking about problems in bioethics and affects which allocative principles seem plausible. ${ }^{\text {IO }}$ In practice, particularly when it comes to the allocation of resources for medical care, we think that the difference principle would be

${ }^{6}$ We do not engage here with the debate about exactly what egalitarians should seek to equalize that is, what the ultimate currency of distributive justice is - but assume that it is something like opportunities to flourish, where flourishing is synonymous with positive well-being. For a helpful discussion of some key philosophical positions, see Gerald Cohen, "On the Currency of Egalitarian Justice," Ethics 99 (1989): 906-944.

7 For an introduction to political theory that interprets leading theories as attempts to articulate the principle that everyone should be treated as an equal, see Will Kymlicka, Contemporary Political Philosophy, 2nd ed. (Oxford: Oxford University Press, 2002).

${ }^{8}$ Rawls, Theory of Justice, 87.

9 Ibid., 83-84. Norman Daniels has attempted to apply a Rawlsian view to health care (Just Health [New York: Cambridge University Press, 2007]).

ro Feminist scholars have criticized theories of justice like Rawls's that bracket issues of justice outside those that relate to individual workers. See, e.g., Susan Moller Okin, Justice, Gender, and the Family (New York: Basic Books, I989). 
too strict. ${ }^{\text {II }}$ The people who are worst off within high-income countries (HICs) are probably individuals who are born with painful, debilitating congenital conditions that dramatically curtail their life expectancy. ${ }^{\mathrm{I}}$ The difference principle would imply that society should invest vast amounts of money into research and incremental improvements in the quality of life for these individuals, even when far greater benefits could be provided to other patients whose quality of life is not quite as bad but who have greater prospects for improvement. We noted above that a just institution is one that could be justified to each person affected by it. In this case, we would justify to the very worst off not focusing all our resources on them by pointing out how much more could be done with some of those resources if directed to more treatable conditions. Such cases suggest that in justifying unchosen differences in resources there is a balance to be struck between giving higher priority to people who are worse off and maximizing the total benefits that are distributed. ${ }^{13}$ We should care both about the distribution of benefits and about the amount of benefits. ${ }^{\mathrm{I}}{ }^{4}$ Both factors are relevant to a just distribution, consistent with our egalitarian approach.

We are not only egalitarians, but liberal egalitarians. Our liberalism shows up in two important ways. First, we argued in Chapter 5 that there is a strong moral presumption against interfering with the voluntary actions of autonomous individuals, except where it is necessary to protect other parties. This presumption also applies to the state. The state - via the various social institutions that it enables or creates - should give high priority to respecting, protecting, and fulfilling the autonomy rights of individuals. Contrary to libertarian views, however, this liberal defense of autonomy does not imply that redistributing resources is presumptively wrongful. Insofar as a different distribution of resources is required as a matter of justice, the current holders of those resources do not have rights to

I Cf. Derek Parfit, "Equality and Priority," in Andrew Mason (ed.), Ideals of Equality (Oxford: Blackwell, I 998), I-20; Dennis McKerlie, "Equality," Ethics Io6 (I996): 274-296; and Richard Arneson, "Egalitarian Justice versus the Right to Privacy," Social Philosophy and Policy I7 (2000): 9I-II9.

I2 Examples include Tay-Sachs disease, Lesch-Nyhan syndrome, and juvenile Batten disease, which we discuss in Chapter 8.

${ }^{13}$ Compare Norman Daniels, "Justice, Health, and Healthcare," American Journal of Bioethics I (2) (200I): 2-I6, at 9-IO.

I4 We do not attempt to give a formula for how this trade-off should be made. For some data on public preferences regarding how much priority should be given to those who are worse off, see Koonal Shah, "Severity of Illness and Priority Setting in Healthcare: A Review of the Literature," Health Policy 93 (2009): 77-84. 
them and so do not have autonomy rights with respect to them that the state has a duty to respect.

Second, the state should adopt a default of neutrality among different views people may have about what constitutes a good life. This is partly for reasons of autonomy. It is typically valuable for individuals to lead an autonomous life in which they are able to set and follow their own goals. Some people may aim to live lives that sacrifice their well-being, to some extent, for valued projects. It would be paternalistic to insist that they do otherwise. State neutrality is also justified by reasons of epistemic humility in light of our subjective account of well-being, according to which what is ultimately good for someone depends on what they desire and what they enjoy (Chapter 8). Unsurprisingly, then, people are often the best judges of their own well-being. ${ }^{\text {I5 }}$ Such state neutrality is compatible with recognizing that certain resources are likely to be instrumentally helpful to virtually everyone, regardless of their specific aims and priorities. This idea justifies the state's role in promoting, for example, universal basic education and public health measures.

Finally, we should mention our views on the site of social justice. By the site we mean the sort of entity or agent that is a candidate for being distributively just or unjust. Some writers think that only social institutions - or some subset of social institutions - can be judged according to whether they conform to principles of justice. Others think that we can also criticize individuals on the grounds that their actions lead to unjust outcomes. We accept the latter view. This is because the reasons why we care about how social institutions are set up - such as the substantial effects they have on people's life prospects - also seem to apply to the actions of individuals. ${ }^{\mathrm{I}}$

In many cases, differing views on the site of social justice will not affect specific conclusions about justice in bioethics. But occasionally it will matter. To illustrate, consider the challenge many health systems face of ensuring sufficient coverage for rural communities. Those who think that only social institutions are amenable to criticism on the basis of justice may argue that governments or community health providers are responsible for

is Cf. John Stuart Mill, On Liberty (London: Parker \& Son, I859), 91-92. Note that this need not entail state neutrality about how (nonautonomous) children should be raised, since neither consideration - the value of autonomously directing one's own life and epistemic humility applies in the same way.

${ }^{16}$ For an accessible overview of this debate and an argument in favor of judging individual actions as well as social structures, see G. A. Cohen, If You're an Egalitarian, How Come You're So Rich? (Cambridge, MA: Harvard University Press 2000). 
incentivizing doctors to work in remote areas. Those who take the contrary view will say that doctors who refuse to work in rural communities unless they are given much higher pay are also open to criticism.

To summarize, according to the liberal egalitarianism we endorse:

I. Unchosen differences between individuals in terms of their opportunities to flourish are presumptively unjust.

2. In justifying unchosen differences a balance must be struck between giving higher priority to people who are worse off and maximizing overall benefits.

3. Infringements on individual liberty require substantial justification.

4. The state should be neutral among competing conceptions of the good life for an individual.

5. We may evaluate individuals, as well as institutions, in terms of justice.

It is worth noting four questions within liberal egalitarianism on which we have not taken a position.

First, though we maintain that the distribution of resources is critical to justice, we have not spelled out precisely how to conceptualize distributive concerns. Regarding the egalitarian criterion of distribution, we have left open whether it is ultimately about equality per se (a comparative notion) or about helping those who are worse off (a prioritarian notion). Normally, helping the worse off will promote equality, and vice versa, but in principle the two aims can diverge. ${ }^{17}$ We have also not committed to any precise way of weighing the egalitarian criterion (whether conceptualized ultimately as equality or priority) against other considerations, such as maximizing the amount of benefit that can be distributed. We regard this as a task that will involve intuitive weighing and might not be susceptible to more structured analysis.

Second, we endorsed the "luck egalitarian" thesis that chosen inequalities are not unjust. This implies that, in principle, people can be held responsible for their decisions and the consequences of those decisions. But we have not said under what conditions a choice is voluntary and informed enough that someone should be held responsible for its consequences. In bioethics, this issue arises when someone's behavior can influence their

${ }^{17}$ For an argument that this distinction will rarely make a difference in practice, see Marc Fleurbaey, "Equality versus Priority: How Relevant Is the Distinction?," Economics \& Philosophy 3 I (20 I 5): 203-2I7. 
health. For example, diet and exercise affect the likelihood that someone will develop type II diabetes. For some, this connection implies that it would be acceptable for public health providers and private insurers to incentivize healthful behaviors and penalize risky behaviors. ${ }^{18}$ Others consider such policies unwarranted because they deny that the bad outcomes are chosen sufficiently voluntarily and knowingly for people to be legitimately held responsible for them. ${ }^{19}$ Furthermore, many individuals whose health behaviors are associated with negative health outcomes are unjustly disadvantaged in other ways. For example, in HICs, smoking is negatively correlated with socioeconomic status. ${ }^{20}$ Even if such individuals are responsible for some part of their ill health, they are already deserving of much better treatment by state institutions than they currently receive. ${ }^{2 \mathrm{I}}$

Third, it is one thing to identify a social injustice and another to say what policy responses are appropriate ways to address it. For example, unjust inequalities in wages might be appropriately redressed through legal systems that empower collective bargaining, set minimum standards for compensation, and institute a progressive taxation system to fund government programs. By contrast, unjust inequalities that resulted from employers discriminating on the basis of race or gender would not be appropriately addressed by simply paying more to those who were discriminated against. For some important bioethical questions, the acceptable policy responses are hotly debated. For example, someone with a disability may be unjustly disadvantaged in getting and keeping jobs as a result of their disability. One response would be to try to "correct" disabilities as much as possible through medical intervention. Another is to reduce the disadvantages through providing a more accommodating environment, such as wheelchair-accessible workplaces and flexible working hours. A third is to provide additional benefits, such as monetary support, to individuals with disabilities that impede their ability to work.

I8 A. M. Buyx, "Personal Responsibility for Health as a Rationing Criterion: Why We Don't Like It and Why Maybe We Should," Journal of Medical Ethics 34 (2008): 87 I-874.

i9 Rebecca Brown, "Moral Responsibility for (Un)Healthy Behaviour," Journal of Medical Ethics 39 (2013): 695-698.

20 Rosemary Hiscock et al., "Socioeconomic Status and Smoking: A Review," Annals of the New York Academy of Sciences I 248 (2012): I07-I 23.

${ }^{21}$ Eric Cavallero, "Health, Luck, and Moral Fallacies of the Second Best," Journal of Ethics I 5 (20 I I): 387-403. A policy that holds people responsible for some negative health outcomes also needs a fair method for determining which health outcomes people are responsible for. Given the multitude of influences on health outcomes - behavioral, environmental, and genetic - and the multiple possible influences on behavior, it is typically very hard to determine which individual health outcomes are the result of voluntary decisions. 
Depending on the context, there may be very good reasons to prefer one of these ways of responding to unjust differences in opportunities to flourish to others. ${ }^{22}$

A fourth, and related, question concerns the extent to which egalitarians should consider issues other than the distribution of resources. Critics of luck egalitarianism have argued, among other things, that it has focused too much on redistribution and neglected the importance of the relationships in which individuals in a society stand to one another. ${ }^{23}$ For example, the successful businessman who is discriminated against because he is black or gay suffers injustice, but the injustice results not from maldistribution of resources but from failure to treat him as an equal. As Nancy Fraser put it, egalitarians should care about "recognition," not only about "redistribution." ${ }^{24}$ We do not seek to take a position on this debate here. However, we acknowledge that our primary focus is indeed on the distribution of benefits. This is not because we think these other concerns do not matter. Rather, given limited space, it is more important for the development of our theory to show its links with individual obligations of beneficence, which also concern distributing benefits.

Though these four questions are important and sometimes relevant to policy, liberal egalitarians who disagree about them still share extensive common ground. In many cases, as we hope this chapter demonstrates, this common ground is sufficient to give guidance regarding questions of bioethics.

\section{Rejecting Libertarianism}

In high-income Anglophone countries, the most prominent alternatives to liberal egalitarian views of distributive justice are libertarian views. ${ }^{25}$ Though defended by relatively few academics who work on justice, they have been very influential in the wider political culture. Libertarians

22 J. Wolff, "Disability among Equals," in Kimberly Brownlee and Adam Cureton (eds.), Disability and Disadvantage (New York: Oxford University Press, 2009), I I 3-I 37.

23 Elizabeth Anderson, "What Is the Point of Equality?," Ethics I09 (1999): 287-337. For some responses, see Kok-Chor Tan, "A Defense of Luck Egalitarianism," Journal of Philosophy ros (2008): 665-690; and Kasper Lippert-Rasmussen, Luck Egalitarianism (London: Bloomsbury, 2016).

${ }^{24}$ Nancy Fraser, "Social Justice in the Age of Identity Politics: Redistribution, Recognition, and Participation," in Nancy Fraser and Axel Honneth, Redistribution or Recognition? (New York: Verso, 2003), 7-109.

${ }^{25}$ Utilitarianism also provides an alternative account of the requirements of distributive justice. We present our reasons against adopting utilitarianism as a moral theory in Chapter 3. 
prioritize individual autonomy rights, including negative rights against interference with persons and their property. ${ }^{26}$ They deny that it is permissible for the state to use people's property except in order to secure the resources necessary to enforce autonomy rights. Consequently, libertarians typically reject the sort of wholesale and ongoing redistribution of resources - as provided, for example, by public health care programs and unemployment benefits - that egalitarians support. ${ }^{27}$

Libertarian views would have very different implications for many issues in bioethics than the liberal egalitarianism we just defended. For example, Tristram Engelhardt argues:

Rights to health care constitute claims against others for either their services or their goods. Unlike rights to forbearance, which require others to refrain from interfering, rights to beneficence require others to participate actively in a particular understanding of the good life. Rights to health care, unless they are derived from special contractual agreements, depend on the principle of beneficence rather than that of autonomy, and therefore may conflict with the decisions of individuals who may not wish to participate in realizing a particular system of health care. ${ }^{28}$

The upshot, for Engelhardt, is that there is no moral right to health care. We reach the opposite verdict in this chapter's penultimate section. Given the substantial disagreement between our conception of justice and the libertarian approach, we think it important to explain why we think libertarianism is mistaken. ${ }^{29}$

For the libertarian, the way that resources are ultimately distributed in a society is not what matters for justice. What matters for justice is the process through which the distribution of resources comes about. Provided that someone legitimately acquires a resource, it is up to her how to dispose

${ }^{26}$ For prominent statements of this position, see F. A. Hayek, The Constitution of Liberty (Chicago: University of Chicago Press, I960); Robert Nozick, Anarchy, State, and Utopia (New York: Basic Books, I974); and Jan Narveson, The Libertarian Idea (Philadelphia: Temple University Press, 1988).

27 For the purposes of discussion, we set aside so-called left libertarians, who share libertarian views about the importance of individual self-ownership, but have much more egalitarian views about the distribution of natural resources. See, e.g., Michael Otsuka, Libertarianism without Inequality (Oxford: Clarendon, 2003); and Peter Vallentyne and Hillel Steiner, Left Libertarianism and Its Critics (New York: Palgrave, 2000).

${ }_{28}$ Tristram Engelhardt, The Foundations of Bioethics (New York: Oxford University Press, I986), 336.

29 By contrast, other competing political theories either would tend to have similar implications for many questions in bioethics (such as moderate communitarian views) or are no longer prominent in political debates or in the bioethics literature (such as Marxism). 
of it. If others interfere with how she disposes of her resources, they violate her rights. ${ }^{30}$ This includes interfering in order to redistribute the resources to those who need them more. By contrast, liberal egalitarians can endorse the allocation and reallocation of resources according to individuals' present needs.

In order to defend their view, libertarians need to explain how individuals obtain rights over resources in the first place. One way to obtain property rights over an object is for someone to make the object out of resources they already own. For example, if I build a house on land I own with materials that I buy, then I will own the house. This prompts the question of how individuals came to own the resources that they use to make other things. For most resources, this comes about through a transfer of property rights: one person gives a resource to a second person. But, of course, this will be a legitimate way to obtain rights to a resource only if the first person already had a legitimate claim to the resource. In turn, that person will have had a legitimate claim to the resource only if she received it from someone who had a legitimate claim, and so on. Somehow, the initial acquisition of individual property rights over resources must be justified. This poses what we believe are insuperable challenges for the libertarian approach to justice.

The first challenge is that the actual processes by which private property in land and other resources were originally acquired were clearly not legitimate in most cases. For example, land in the Americas was mostly acquired through the conquest and displacement of native peoples by colonizing Europeans. Land title in European countries traces back to similarly inglorious events. ${ }^{3 \mathrm{I}}$ The libertarian must either accept that acquiring property by force is a legitimate way to obtain it (in which case it may be taken from its present owners) or, more plausibly, say that it is not (in which case the current ownership of a great deal of property is illegitimate on their view). ${ }^{32}$

The second challenge is that it is difficult to find a principled justification for the initial acquisition of private property, even for a hypothetical case. Many libertarians look to John Locke`s labor-mixing theory of

30 Nozick, Anarchy, State, and Utopia, chap. 7.

3I For example, much land in the United Kingdom is privately owned as a result of its removal from common use during the "enclosures." Enclosure was the source of considerable resistance from the rural poor who were thereby deprived of access to fruits of the land. See Pauline Gregg, Modern Britain (New York: Pegasus, 1965).

32 Kymlicka, Contemporary Political Philosophy, I I I. 
property rights for a justification of the initial acquisition of property. ${ }^{33}$ Since I own my body, I own my body's labor. If I mix my labor with unowned materials, I thereby gain ownership of the product of that mixing, as well. This acquisition is subject to the proviso that there is "enough, and as good, left in common for others." 34

The proviso, taken literally, cannot be met in the modern world, since most of the earth's resources are now privately owned - there is definitely not enough and as good left for people who are born now. Acknowledging this, libertarians such as Robert Nozick argue that the proviso should be interpreted as saying that the acquisition of private property is legitimate only when it does not make anyone worse off. Yet, interpreted this way, the proviso seems unjustified because a transaction might treat someone unfairly even if it does not make them worse off. Suppose that some area of outlying land is jointly held by a town's residents. Each resident, we suppose, might be better off if the land were the private property of a small number of people: this would be more efficient than common ownership, the landowners could employ the landless, and so on. Thus the proviso is met and a small group of individuals claim the land. However, it might be that this group is much better off as a result of becoming landowners, while the others, now waged laborers, are only slightly better off than before. How is it that the small group can claim so much of the gains of the new system just by virtue of working on this land first? And, given how important autonomy rights are for the libertarian, how is it that they do not need the others' consent for the acquisition? Again, the problem is particularly stark when we think about generations born after most land is already divided up. They had no opportunity to labor on the land first, and so had no chance to be the ones who benefited most - and, of course, they had no opportunity to consent to the acquisition. ${ }^{35}$

It might seem that a one-time redistribution of resources could meet both challenges. The redistribution would establish a starting point at which everyone had a fair share of resources. After that, the libertarian might argue, it should be up to each person to decide what they do with their property. No further redistribution should be allowed.

\footnotetext{
33 John Locke, Second Treatise of Government, ed. C. B. Macpherson (Indianapolis: Hackett, I980/ I690), chap. V. See also, e.g., Nozick, Anarchy, State, and Utopia, chap. 7.

34 Locke, Second Treatise of Government, chap. V, para. 27.

35 Compare G. A. Cohen, Self-Ownership, Freedom, and Equality (Cambridge: Cambridge University Press, I995), 79-87. See also Kymlicka, Contemporary Political Philosophy, I07-I 27.
} 
However, this proposal fails on at least two counts. First, it does not help with the problem of new people entering the population. How is their share of natural resources to be worked out? Second, it does not address the fundamental counterintuitive aspect of the libertarian's view. No matter what choices people make, they will end up with very unequal amounts of resources and opportunities to flourish. This is because in every generation some people will be given more resources than others (for example, through inheritance or education), some people will have greater opportunities than others (for example, because they have abilities that are more highly valued), and some people will be unlucky (for example, children whose parents die or do not provide for them). For the egalitarian, such cases drive the perception that unchosen differences in opportunities for flourishing are unfair and should be corrected. The libertarian has to bite this counterintuitive bullet.

Note that although we reject libertarianism as a theory of distributive justice, this does not mean that we always oppose the use of markets for distributing goods. Under certain conditions markets are very efficient ways to incentivize the production of needed goods. The liberal egalitarian can happily support the existence of markets in goods and services for these instrumental reasons. But they are instrumental reasons: she is also willing to constrain those markets in cases in which doing so would produce more just outcomes. Market transactions can also be one way in which individuals exercise autonomy rights over their persons or property. There is therefore a strong presumption against interfering with them, except when they lead to unjust outcomes or otherwise involve wrongdoing.

\section{Global Justice: A Defense of Cosmopolitanism}

We have argued that unchosen differences in opportunities to flourish within a society are prima facie unjust. Within certain constraints social institutions should be set up in order to mitigate those differences. But, in our nonideal world, there are not only substantial differences in outcomes between compatriots; there are huge differences between people across national borders. Take life expectancy, which is a good summary indicator of expected well-being. Life expectancy for a child born in Sierra Leone in 2018 was fifty-four years. ${ }^{36}$ For a child born in Japan it was eighty-four

${ }^{36}$ The data come from the World Bank, World Bank Open Data (available at https://data.worldbank.org; accessed August I 8, 2020). 
years. ${ }^{37}$ The thirty-year difference cannot be plausibly ascribed to differences in voluntary decisions made by individuals in the two countries. Rather, it results from massive differences in material wealth, nutrition, access to health care, and so forth. ${ }^{38}$ Gross domestic product (GDP) per capita is $\$ 43,240$ in Japan and only $\$ \mathrm{I}, 790$ in Sierra Leone. ${ }^{39}$ Globally, 734 million people live in extreme poverty, ${ }^{40} 2$ billion lack access to improved sanitation facilities (with nearly 700 million defecating in the open), ${ }^{4 \mathrm{I}}$ and 785 million do not have access to a basic water service. ${ }^{42}$ An estimated 5.3 million children under the age of five die each year. ${ }^{43}$ The average under-five mortality rate in low-income countries is fourteen times greater than the average rate in HICs. Literacy rates vary from 43 percent in Afghanistan to almost roo percent in HICs. ${ }^{44}$ Like many other important outcomes, literacy is also gendered: of the 750 million illiterate adults in the world, nearly two-thirds are women. ${ }^{45}$

What is the ethical significance of these transnational differences in individual prospects? The intuitive judgments that motivated liberal egalitarianism in the case of the state might seem to support treating these differences in the same way. The nation into which someone is born is unchosen and appears morally arbitrary - that is, there seems to be no sense in which one person deserves a worse life than another in virtue of having been born in a different country. Consequently, the vast differences

37 Ibid.

${ }^{8}$ In any case, the large difference in life expectancy - an average measure - is substantially a product of much greater child mortality in Sierra Leone, for which the question of individual responsibility cannot arise.

39 World Bank, World Bank Open Data (available at https://data.worldbank.org; accessed August I 8, 2020). Gross domestic product represents the monetary value of all finished goods and services produced within a country's borders. These figures are in 2017 international dollars adjusted for purchasing power parity. An international dollar has the same purchasing power in a specific country as a US dollar has in the United States. It thereby takes account of the differences in the cost of goods and services in different countries.

40 These are data for 2015 (available at www.worldbank.org/en/topic/poverty/overview; accessed August I8, 2020). Extreme poverty is defined by the World Bank as less than \$I.90 international dollars per day (so, for US readers, this is the equivalent of $\$ 694$ annually for all expenses, including housing, food, transport, medical care, and schooling).

4I UNICEF, "Sanitation" (June 20I9; available at https://data.unicef.org/topic/water-and-sanitation/ sanitation/; accessed August I 8, 2020).

42 UNICEF, "Drinking Water" (June 2019; available at https://data.unicef.org/topic/water-andsanitation/drinking-water/; accessed August I 8, 2020).

43 These 2018 data are from World Health Organization, Global Health Observatory (available at www.who.int/gho/child_health/mortality/mortality_under_five_text/en/; accessed August I 8, 2020).

44 The World Bank, World Bank Open Data (available at https://data.worldbank.org; accessed August I 8,2020 ).

45 US Central Intelligence Agency, World Factbook (available at www.cia.gov/library/publications/ resources/the-world-factbook/fields/370.html; accessed August I 8, 2020). 
in life prospects between individuals born in different countries seem as unjust as they would if they arose between compatriots. Considerations like these support a cosmopolitan view of global justice: principles of justice apply in the same way across states as they do within states. ${ }^{46}$

For some theorists, this extrapolation from the national to the international context is unwarranted. While unchosen and arbitrary differences indicate injustice within a society, the existence of such differences is not sufficient for principles of justice to apply. Instead, these statists argue, the fact that conationals are part of the same society is necessary for differences between them to matter. ${ }^{47}$ Rawls writes:

For us the primary subject of justice is the basic structure of society, or more exactly, the way in which the major social institutions distribute fundamental rights and duties and determine the division of advantages from social cooperation. ${ }^{48}$

If the existence of the "basic structure" is a precondition for concern about distributive justice, and if there is no such basic structure internationally, then it is a mistake to apply our liberal egalitarian views to the global distribution of resources. ${ }^{49}$

For this statist response to be compelling, it must be true both that there is no global basic structure and that the existence of a shared basic structure is indeed necessary for questions of distributive justice to arise. Both claims are dubious. ${ }^{5 \circ}$

First, as various theorists have argued, the extent of international interdependence and shared global institutions is great enough that we should

${ }^{46}$ Cosmopolitanism is defined in various ways. See Charles Beitz, "Rawls's Law of Peoples," Ethics I IO (2000): 669-696, at 677; Thomas Pogge, "Cosmopolitanism and Sovereignty," Ethics I03 (I992): 48-75, at 48-49; and Gillian Brock, Global Justice (Oxford: Oxford University Press, 2009), I I-I 4. Our particular choice of terminology should not beg any substantive questions.

47 Statists need not deny that we have some obligations to people living outside our national borders. They can agree, for example, that we have duties not to harm foreigners and even duties of beneficence to benefit foreigners who are especially needy. The key point is that these duties do not result from relative differences in people's prospects. We return to this point shortly.

${ }^{8}$ Rawls, Theory of Justice, 6.

49 Whether Rawls believed that there is no global basic structure is a matter of interpretation (see Arash Abizadeh, "Cooperation, Pervasive Impact, and Coercion: On the Scope [not Site] of Distributive Justice," Philosophy \& Public Affairs 35 [2007]: 318-358, at 319 note 3). In any case, this view is implicit in Rawls's writing and he certainly denies that the same principles apply globally as apply domestically (see John Rawls, The Law of Peoples [Cambridge, MA: Harvard University Press, 200I]).

so See Abizadeh, "Cooperation, Pervasive Impact, and Coercion," for a comprehensive treatment of the several possible conceptions of the basic structure and an argument to show that each leads to the conclusion that distributive justice is global in scope. 
be concerned about the distribution of resources internationally as well as intranationally. ${ }^{5 \mathrm{I}}$ All states are heavily dependent on trade for their economic prosperity, so the policies (including internal policies) of other countries also affect them. For example, tax breaks for corporations in one country can negatively affect other countries by incentivizing the movement of capital. Immigration policies that target highly educated individuals may contribute to a "brain drain" from poorer to richer countries. The fact that other countries typically treat the de facto controller of a territory as its legitimate government allows autocratic governments to sell natural resources and borrow money in the name of their people. These international resource and borrowing privileges encourage autocratic governments, coups, civil war, and corruption. ${ }^{52}$

In addition to the substantial effects policies in one country can have on another, there are global institutions that regulate global affairs. Important global institutions include the various organs, subsidiaries, and agencies of the United Nations System - which include the World Bank and the World Health Organization - as well as the World Trade Organization (WTO). The WTO illustrates nicely why some theorists think there is, contrary to the statist's claim, a global basic structure. Currently, I64 states are WTO members and another twenty-two are observers, thereby covering the vast majority of the world. According to WTO figures, 96.4 percent of world trade is accounted for by WTO members, who govern 90.I percent of the world's population. ${ }^{53}$ WTO members have sixty agreements, implemented through domestic legislation, that cover trade in goods and services, intellectual property laws, technical standards, food safety, and many other areas. Membership also involves commitment to a dispute settlement mechanism through which compliance with the other agreements is enforced. ${ }^{54}$ Thus, becoming a WTO member involves signing up to a large number of far-reaching rules that affect all aspects of economic life and can be coercively enforced. Nor, given the WTO's global coverage and the trade opportunities it affords, is there much of an option for countries who would prefer a different system. Perhaps state

5I See Charles Beitz, Political Theory and International Relations (Princeton, NJ: Princeton University Press, 1979); and Allen Buchanan, "Rawls's Law of Peoples: Rules for a Vanished Westphalian World," Ethics i io (2000): 697-721.

52 Thomas Pogge, World Poverty and Human Rights (Cambridge: Polity, 2002), I I 2-I I6.

53 World Trade Organization, Handbook on Accession to the WTO, Chapter I (available at www.wto .org/english/thewto_e/acc_e/cbt_course_e/cisipi_e.htm; accessed August I 8, 2020).

54 World Trade Organization, "Understanding the WTO: Settling Disputes" (available at www.wto .org/english/thewto_e/whatis_e/tif_e/dispi_e.htm; accessed August I8, 2020). 
governments impose more rules, with greater effects on individuals' lives, but even if so, this seems to be a difference of degree rather than kind. ${ }^{55}$

Second, even if a shared basic structure would require more extensive social institutions than the current global order constitutes, we may ask why these more extensive institutions are necessary in order for principles of distributive justice to apply. Rawls suggests an answer in saying that the "basic structure is the primary subject of justice because its effects are so profound and present from the start." ${ }^{56}$ But this will hardly separate the domestic from the international case: as the statistics cited above show, whether someone is born into a poor or a rich country makes a huge difference to their life prospects.

We think that the arguments in favor of some sort of cosmopolitanism are compelling. However, we acknowledge that this is an area of considerable disagreement and we have only scratched the surface of an ongoing debate. ${ }^{57}$ For this reason, it is important to note that even noncosmopolitans generally acknowledge obligations to foreigners in severe need. Rawls, for example, claimed that there is a duty of assistance to "other peoples living under unfavorable conditions that prevent their having a just or decent political and social regime." ${ }^{8}$ This duty has a cutoff - the point at which everyone is living under conditions sufficient to secure their basic needs. But were this duty to be fulfilled, it would dramatically transform the situation of people living in poverty.

\subsection{Individuals and the Demands of Beneficence}

\section{General Considerations}

So far we have examined - through the lens of distributive justice - the ways in which institutions are ethically required to benefit people.

55 Michael Blake argues that the state is distinctive because of its way of coercing its residents ("Distributive Justice, State Coercion, and Autonomy," Philosophy \& Public Affairs 30 [200I]: 257-296). Cf. Thomas Nagel, "The Problem of Global Justice," Philosophy \& Public Affairs 33 (2005): I I 3-I 47. For a response, see Abizadeh, "Cooperation, Pervasive Impact, and Coercion."

56 Rawls, Theory of Justice, 7.

57 For example, we have not even touched on arguments that seek to justify partiality to conationals on the basis of shared nationality, which may obtain independently of sharing a state (see, e.g., David Miller, On Nationality [Oxford: Clarendon, I 995]).

58 Rawls, Law of Peoples, 37. Compare Nagel: "The facts are so grim that justice may be a side issue ... some form of human assistance from the well-off to those in extremis is clearly called for quite apart from any demand of justice, if we are not simply ethical egoists. The urgent current issue is what can be done in the world economy to reduce extreme global poverty" ("The Problem of Global Justice," I I 8). 
Individual agents have related obligations. Some include individuals' obligations to obey the law and play their part in supporting (sufficiently) just institutions. ${ }^{59}$ Questions of civil obedience and disobedience - as well as the fundamental question of whether the state can be justified to those who live within it - are fascinating and important. ${ }^{60}$ However, we lack the space to address them.

In addition to their duties to support and comply with just institutions, individuals have duties of beneficence that require them to provide benefits to others in need (either directly or indirectly - for example, through institutional means). That we have some such duties is suggested intuitively by examples such as the classic pond case. ${ }^{61}$ Suppose you are an ablebodied adult walking by a large pond. In the pond you notice a struggling child. Though the child is very likely to drown unless aided, the pond is only a meter deep, so you could safely wade out to save him. If you did so, however, the muddy water would likely ruin your suit. No one else is around. Do you have a duty to save the child? Most people agree that you do; indeed, someone who walked on by would be regarded as a moral monster.

Thought-experiments like the pond case suggest that we are sometimes morally required to assist others at some cost to ourselves. Everyday moral thinking also suggests that there are limits on this requirement to assist. I do not have a duty to benefit another every time I could provide a greater benefit to them than the corresponding cost to myself. Agents appear to have a limited liberty - or "prerogative" - to act in ways that do not maximize the good consequences of their actions.

On the surface, these so-called agent-centered prerogatives might seem mysterious. After all, from a neutral perspective my interests are no more important in virtue of being mine than yours are in virtue of being yours. What makes it acceptable for me to prefer myself rather than doing what is best for everyone?

Note, first, that there is a strong intuitive case for the view that asserts that it is sometimes impermissible to favor one's own interests but also

59 Rawls, Theory of Justice, 99-100.

${ }^{60}$ On civil disobedience, see Hugo Adam Bedau (ed.), Civil Disobedience in Focus (New York: Routledge, 2002). On possible sources of political obligations, see A. John Simmons, Moral Principles and Political Obligations (Princeton, NJ: Princeton University Press, I98I). In bioethics such questions arise, for example, regarding clinicians who have conscientious objections to carrying out abortions or breaking patient confidentiality to assist law enforcement officials.

6I For the classic description of the case, see Peter Singer, "Famine, Affluence, and Morality," Philosophy \& Public Affairs I (I972): 229-423, at 23 I. 
sometimes permissible not to do what is impartially best. ${ }^{62}$ That is, it is intuitively plausible that we have some duties of beneficence, but those duties are limited. Nonetheless, as we stress in multiple places in this book, an initially intuitive view can still be mistaken. We therefore need a principled justification for it as well.

The agent-centered prerogative is a particular type of right, which consists in the liberty not to maximize the good consequences of one's actions. We think that the ground for this right is of the same type as for many other rights: the important interests that it protects. Having agentcentered prerogatives allows autonomous individuals to flourish because it allows them to set their own goals and pursue their own projects according to what they find valuable. ${ }^{63}$ This acknowledges that each person's point of view has special weight for her and thereby takes her seriously as someone whose values and goals give her reasons, not merely treating her as a means to making the world a better place. Respecting agentcentered prerogatives, then, is one way in which we show respect for rights-holders (one of the two foundational values in our ethical theory).

We have argued that agents are sometimes morally required to benefit others and are sometimes permitted not to benefit others when they could. It is worth emphasizing that the view does not imply that our starting judgments about how much we should care about the interests of others and how much we are permitted to benefit ourselves are correct or close to correct. That will depend on the results of using the method of reflective equilibrium, which can lead to dramatic revisions in what we believe we ought to do (Chapter 2).

To get a handle on the extent of our duties to benefit others we must explore the grounds for the duty of beneficence. Duties of beneficence arise in response to the morally important needs of others. The strength of those duties is plausibly greater the more significant the benefits someone could provide. All else being equal, it is morally more important to save someone's life than to save them from losing a limb, and, consequently, their claim to help is greater. Likewise, the strength of the duties is

62 Shelly Kagan describes three positions: extremist, moderate, and minimalist. The extremist claims that we must always act in a way that is impartially optimal. The minimalist denies that we are ever morally required to benefit others. Kagan argues that moderate views that lie between these two extremes are unsustainable (The Limits of Morality [Oxford: Clarendon Press, 1989]).

${ }^{6}$ For discussions of this theme, see Samuel Scheffler, The Rejection of Consequentialism, 2nd edition (Oxford: Oxford University Press, I994); and Bernard Williams, "A Critique of Utilitarianism," in J. J. C. Smart and Bernard Williams, Utilitarianism (Cambridge: Cambridge University Press, I973), I08-II7. 
plausibly greater the lower the cost to the agent of providing that benefit. If all I have to do is wade into the pond and get my clothes wet in order to save a life, then the victim has a stronger claim than if I had to risk my own life to save his. So, as the benefits we could supply to others grows and the cost to us diminishes, their claim to our help increases. ${ }^{64}$

What does this imply about our duties of beneficence? The claims of some potential victims will be strong enough to override an individual agent's prerogative to pursue her own projects. In such cases, the individual acquires a perfect duty of beneficence (the duty to rescue). For claims that are weak enough that they do not override the agent-centered prerogative, she may choose to do something other than fulfill those claims. As noted just above, this prerogative is grounded in considerations such as the value of governing one's own life, pursuing the projects one thinks valuable, and so forth. However, satisfying the interests that this prerogative serves to protect is perfectly possible while responding to some of the morally important need that underlies these claims. A typical agent could sometimes provide benefits to needy others without compromising her ability to govern her own life. She therefore ought to do so. Thus, the combination of morally important need and agent-centered options entails what is called the imperfect duty of beneficence. ${ }^{65}$ This is a duty to provide some benefits to others but where the agent has some discretion about exactly when and how she does so. Having this discretion allows individuals freedom to pursue their interests and allows them to incorporate beneficence into their personal projects.

\section{The Perfect Duty of Beneficence}

We have little further to add regarding the content of the imperfect duty of beneficence and do not regard our interpretation of it as controversial. ${ }^{66}$ The perfect duty of beneficence - or the duty to rescue - is another matter.

${ }^{64}$ Other conditions may apply, too, but we keep the case simple for the moment in order to clarify the underlying normative structure.

65 The terminology of perfect and imperfect duties comes from Immanuel Kant, Foundations of the Metaphysic of Morals, trans. L. W. Beck (New York: Liberal Arts Press, I959/I 785 ). Compare John Stuart Mill: "[D]uties of perfect obligation are those duties in virtue of which a correlative right resides in some person or persons; duties of imperfect obligation are those moral obligations which do not give birth to any right" (Utilitarianism, ed. George Sher [Indianapolis, IN: Hackett, I979/ I 86I ], 48).

66 Relatively little has been written on the imperfect duty of beneficence. One exception is Barbara Herman's work in Kantian ethics. See Herman, "Being Helped and Being Grateful: Imperfect Duties, the Ethics of Possession, and the Unity of Morality," Journal of Philosophy I09 (2012): 39I-4I I, and "The Scope of Moral Requirement," Philosophy \& Public Affairs 30 (200I): 227-256. 
As the pond case illustrates, this duty arises for agents when they are in situations such that they can prevent a very serious harm to another at a low cost to themselves. ${ }^{67}$ Peter Singer, describing what he takes to be a feature of ordinary moral thought, states it in the following way: "If it is in our power to prevent something very bad from happening, without thereby sacrificing anything morally significant, we ought, morally, to do it."

Potential rescue cases are common. For example, a clinician working in a resource-poor setting may encounter patients who are in desperate need but unable to pay for care. Where she could herself provide potentially lifesaving treatment for malaria or take the time to refer someone for cataract surgery to save their eyesight, she has the opportunity to provide a rescue. Clinical researchers may diagnose serious medical conditions in their participants or identify genetic variants that predict increased health risks. Whether they are obliged to inform participants or treat them following these incidental findings may depend on whether the duty to rescue applies. ${ }^{69}$ Any clinician may face a potential duty to warn, which interpreted as an ethical imperative - is best understood as a sort of preventive duty to rescue. This, in effect, was the duty that a majority of justices ascribed to a psychiatrist in the famous Tarasoff case of 1976, in which a psychotherapy patient revealed his intention to kill a specific woman, Tatiana Tarasoff: the psychiatrist's duty to warn, the majority reasoned, overrode his duty of confidentiality to his patient. ${ }^{70}$ Even at the systems level, policy-makers make rescue decisions. For example, the Cancer Drugs Fund that was introduced in England in 20 I I provided funding for National Health Service (NHS) patients to receive expensive cancer drugs that had been assessed as not cost-effective. One charitable interpretation of the motivation behind the fund is that providing access to last-ditch therapies offered a chance of rescue to terminally ill patients. ${ }^{7 \mathrm{I}}$

${ }^{67}$ Compare Beauchamp and Childress on the duty of rescue (Principles of Biomedical Ethics, 206-207) and Rawls on the duty of mutual aid (Theory of Justice, 98).

68 Peter Singer, "Famine, Affluence, and Morality," 23I. He originally states a stronger version of the principle: "If it is in our power to prevent something bad from happening, without thereby sacrificing anything of comparable moral importance, we ought, morally, to do it" (ibid.).

69 For an overview of ethical considerations pertaining to incidental genetic findings, see Gabrielle Christenhusz, Koenraad Devriendt, and Kris Dierickx, "To Tell or Not to Tell? A Systematic Review of Ethical Reflections on Incidental Findings Arising in Genetics Contexts," European Journal of Human Genetics 2I (2013): 248-255.

70 Tarasoff $v$. Regents of the University of California, I7 Cal. 3d 425 (I976); I 3 I California Reporter I 4.

${ }^{71}$ The Cancer Drugs Fund (CDF) was widely criticized as a waste of scarce resources and an inappropriate prioritization of cancer patients over other patients. Following a parliamentary review it was incorporated into the body making other decisions about which of new 
Whether the duty to rescue applies to a situation is clearly very important. If it does, then the potential rescuer is under a stringent moral duty to act. We therefore need to assess carefully which considerations are relevant to the duty.

Two considerations that are sometimes thought to be relevant are the proximity and the identifiability of the victim. Faced with a child drowning in front of me, it is clear to all that I ought to attempt to save her. We appear to be much more blasé about more distant and less individually identifiable victims. For example, it is widely regarded as optional whether I give money to help the victims of natural disasters in other countries, even in the face of starvation or outbreaks of easily treatable diseases.

We think that neither of these considerations is in fact morally relevant. First, upon reflection it is implausible that one's proximity to a victim or one's ability to identify in some way who that victim is should be relevant to a duty to help them. Such considerations do not play a role elsewhere in our moral theorizing and seem inconsistent with the idea that persons matter equally. ${ }^{72}$ Thus, there is a burden of proof on those who would defend their relevance here. ${ }^{73}$

Second, the considerations that seem most likely to underlie duties of beneficence do not require reference to proximity or identifiability. Most salient, in this regard, are the need of the potential beneficiary and the ability of the agent to meet that need, which presumably play a central role in explaining duties to provide benefits. ${ }^{74}$

Third, in cases where proximity and identifiability affect our moral judgments, there are usually alternative explanations. These take both normative and empirical forms. Consider how we might explain why an individual judges it morally imperative to save the child in the pond at the cost of her expensive suit but does not donate a similar amount of money

technologies the NHS should fund: the National Institute for Health and Care Excellence (NICE). A review concluded that the "CDF has not delivered meaningful value to patients or society" (A. Aggarwal et al., "Do Patient Access Schemes for High-Cost Cancer Drugs Deliver Value to Society? Lessons from the NHS Cancer Drugs Fund," Annals of Oncology 28 [2017]: 1738-I750).

${ }^{72}$ Cf. Dan Brock's use of the "Principle of the Equal Moral Worth of All Human Lives" in his "Identified versus Statistical Lives: Some Introductory Issues and Arguments," in I. Glenn Cohen, Norman Daniels, and Nir Eyal (eds.), Identified versus Statistical Lives (New York: Oxford University Press, 2015), 43-52, at 43.

${ }^{73}$ For one attempt to defend the relevance of proximity, see Frances Kamm, Intricate Ethics (New York: Oxford University Press, 2007), 386-388. Her justification in terms of the agent-centered prerogative is too thinly articulated for us to evaluate properly. For arguments for and against the relevance of identifiability, see Cohen, Daniels, and Eyal, Identified versus Statistical Lives.

74 We consider the relevance of roles and special relationships shortly. Here we are concerned only with general duties of beneficence. 
to a charity distributing bed nets to prevent malaria transmission. Normatively, we might defend her decision on the grounds that she judges it much less certain that her money will save a child's life than that her wading into the pond will do so. That is, despite the charity's claims, she does not think that the cost per life saved is really the same. Empirically, we might explain her tendency to make judgments like these in terms of the evolution of our moral sensibilities. Humans evolved living in small groups where the plight of those we could help was salient because they were close and identifiable. ${ }^{75}$ Our strongest impulses to help arise when we empathize with the situation of another. ${ }^{76}$ Thus, it is unsurprising that the urge to rescue is more powerful when we are dealing with a local situation involving a particular person.

Although we think that proximity and identifiability are morally irrelevant in themselves, they may to some extent track considerations that matter. As just noted, more distant rescue scenarios are often ones about which we have much less information and so are likely to be much less certain about the effectiveness of our actions. Whereas the person who jumps into the pond to save a child might have a good idea of whether she can reach him and whether he would drown without her help, this is not always true of the victims of famines or natural disasters. The need may be very real, but whether we can have a beneficial effect may be much more dubious. This skepticism is borne out by data about the effectiveness of many - though not all - attempts to aid distant others. Government-togovernment aid, for example, has been notoriously ineffective in improving development outcomes. ${ }^{77}$ And donations to causes that are highly salient, such as in the immediate aftermath of natural disasters, often result in minimal incremental benefit to victims, given other available resources. ${ }^{78}$

The fact that we are sometimes right to be skeptical about whether a particular action - like donating to a charity - will have its intended effect should not engender global skepticism about our ability to help. Instead, it illustrates the importance of taking uncertainty into account in assessing the cost-effectiveness of our actions and the importance of collecting data

75 See, e.g., Joshua Greene, Moral Tribes (New York: Penguin, 2013).

${ }^{76}$ See, e.g., Martin Hoffman, Empathy and Moral Development (Cambridge: Cambridge University Press, 2000).

77 See Carol Lancaster, Aid to Africa (Chicago: University of Chicago Press, 1999); and Christopher Coyne, Doing Bad by Doing Good (Stanford, CA: Stanford University Press, 2013).

${ }^{78}$ Benjamin Hilton, "Heart vs. Mind: A Review of Emergency Aid" (August I, 20I4); available at www.givingwhatwecan.org/post/201 4/08/heart-vs-mind-review-emergency-aid/). 
to reduce that uncertainty. The latter point is obscured when we think about pond cases, which are one-off events. ${ }^{79}$ Other potential rescue cases, like those experienced by clinicians and researchers, predictably arise, and so systematic assessment of the costs and benefits of interventions is possible.

The costs to the agent of attempting a rescue, the probability of success, and the magnitude of the loss averted for the victim, then, are all clearly relevant to whether a duty to rescue applies. Nevertheless, specifying the limits of the duty has proven challenging. Three types of case illustrate the key challenges. Costly rescues are cases in which it would be possible to rescue someone in great need, but the cost to the agent is not low. For example, malaria researchers in Mali identified a serious congenital heart defect in one of their pediatric participants. ${ }^{80}$ Care was not available for her in Mali, where she consequently faced a high risk of death. She could be airlifted to a European hospital for expensive and possibly life-saving surgery. But were the researchers obliged to do this? ${ }^{81}$ Endless rescues are cases in which it is possible for someone to execute an easy rescue - as with the pond example - but where there are many such easy rescues she could make and she cannot make them all. Some charitable appeals seem to implicate endless rescues: the present authors would be broke before they could provide every child who needs one with an insecticide-treated mosquito net. Clinicians working in very underserved regions may more directly experience this challenge. There may be no apparent end to the patients waiting outside a clinic with serious and treatable conditions. Finally, there are noncompliance cases. Typically, these are cases in which the rescues are costly or endless only because other people are not doing what they should (that is, others are not compliant with the demands of morality).

All of these cases highlight uncertainty about the upper bounds of the perfect duty of beneficence. As we now argue, this turns out to be relatively unproblematic in the ideal case where the burdens of rescue will be fairly distributed. In the nonideal case, it is much trickier.

79 We mean that cases involving individuals happening upon drowning children whom they can easily rescue are exceptional. Drowning, however, is a huge global problem and one of the leading causes of child deaths (World Health Organization, Drowning [fact sheet, updated February 2020; available at www.who.int/mediacentre/factsheets/fs347/en/; accessed September 28, 2020]).

80 Neal Dickert and David Wendler, “Ancillary Care Obligations of Medical Researchers," JAMA 302 (2009): 424-428.

${ }^{81}$ Compare the case of Bob's Bugatti (Peter Unger, Living High and Letting Die [New York: Oxford University Press, I996], I36). 


\section{Individual Duties of Beneficence in a Just World}

In the ideal case, institutions are just and individual agents do what they should. Just institutions would dramatically reduce the number of rescue cases, since morally important needs that could be met are generally ones that would be met in a just society. For example, in a just world, no one would lack adequate nutrition or be sleeping without a bed net in a malaria-endemic region. We could imagine that there would still be unpredictable emergencies - like the child in the pond but they would be very rare. Thus, the problem of endless rescues would not apply. Moreover, since individual agents would be doing what they should, the problem of noncompliance would, by definition, not apply.

There might still be costly rescues. Individual agents might face high financial burdens, as with the child needing expensive surgery. Alternatively, they could find themselves in a position where they had a chance of rescuing someone but the risk to themselves was high. Perhaps they could dash into a burning building to save a child but might themselves be overwhelmed by the smoke.

In the ideal case, however, there are institutional remedies for these problems. Even if a rescue would be ethically required, it might still impose unfair (because unchosen) burdens on the rescuer. If providing such a rescue - such as life-saving surgery - would be extremely expensive, then a just society would presumably reimburse the rescuer for this cost. For example, providing health care funded by taxation is one way in which a country can spread out the costs of providing very expensive interventions to the relatively few people who end up needing them. Institutional remedies like these convert the question of whether an individual should be expected to bear a great cost to benefit another into a question about whether society should collectively bear the cost. It therefore becomes a question of distributive justice.

Other rescue costs are not as easy to distribute across members of society. The risks to the person contemplating running into a burning building cannot be spread out so that everyone gets a single smoky breath. However, there are ways in which even these risks can be managed in an ethical way. For example, rather than relying on untrained passersby, a society can employ professional firefighters. The risks of performing rescues are lower for such professionals: they are trained and equipped to perform specialized tasks. Further, they are usually voluntarily taking on the risks by taking up the profession. Thus, professional duties to rescue 
are one institutional solution to the challenge of costly rescues. ${ }^{82}$ Joel Feinberg states this point as follows:

Each of us has a duty to call the fire department whenever we discover a fire. Beyond that we have no positive duty to fight the flames. That is the special responsibility of the skilled professionals we support with our funds. The reason why we have the duty to report the fire but not the duty to fight it is not just that there is minimal effort required in the one case and not in the other. It is rather that the very strict social duty of putting out fires is most effectively and equitably discharged if it is split up in advance through the sharing of burdens and the assigning of special tasks. ${ }^{83}$

This way of conceptualizing the functions of taxation and professionals who are specialized for particular types of rescue case suggests two further insights. First, taxation can be used to enforce and coordinate the fulfillment of individual duties of beneficence. Second, there may be professional duties of beneficence that are more demanding and more specific than the general duties we have been discussing. These special duties plausibly require that firefighters take on greater risks to save people from fires than members of the public, that lifeguards take on greater risks to save drowning swimmers, and so forth. Germane to our focus in this book, these more demanding duties of beneficence may also apply to medical practitioners. We say more on this topic shortly.

\section{Individual Duties of Beneficence in an Unjust World}

Turn now to the nonideal (actual) case. We do not always have institutions in place that can spread out the burdens of rescue among many people. Moreover, many people and institutions do not do what they should. Some people help only those close and dear to themselves. Others do nothing or actively make things worse by harming or exploiting others. This goes for institutions, too. Whether it be through war, supporting corrupt governments, or imposing unfair terms of trade, governments often make things worse for individuals around the world, even when they have an obligation to make things better.

In the actual world, then, individuals frequently face rescues that appear costly or endless as a result of the noncompliance of others. The researchers

${ }^{82}$ Tina Rulli and Joseph Millum, "Rescuing the Duty to Rescue," Journal of Medical Ethics 42 (2016): $260-264$, at $262-263$.

${ }^{83}$ Joel Feinberg, Harm to Others (New York: Oxford University Press, I984), I70-I7I; see also I $57-159$. 
who faced the question of whether to pay to airlift a child for heart surgery in Europe faced this dilemma because, partly as a result of global injustice, Mali is poor and its health care system is underdeveloped. Similar points apply to clinicians working in environments where there is no limit to the number of patients they could benefit or to those of us living in HICs who would impoverish ourselves before we could make a noticeable dent on the extreme need in the world. Because the majority of people do not do what even a minimal duty to rescue would require, everyone else confronts a world with much greater need. For virtuous agents, the question of where to locate the limits of perfect obligations of beneficence cannot be ignored.

There are differing views on how an agent's responsibilities change when others are not doing what they should. At one extreme is the view that we should treat the noncompliance of others as a fact of nature. For Singer, for instance, each individual has at least a duty to provide benefits to others up to the point where she would be sacrificing something of moral significance. In the face of noncompliance, this would require affluent individuals in HICs to give away much more of their wealth and time than most people think they are obligated to give.

To some theorists, the implications of Singer's view seem unfair. If each of us were to do our duty - that is, if we had full compliance with duties of beneficence - then each of us would have to contribute only a little. Now, the objection goes, many people are not even contributing that little amount (set aside the people who are make things worse). Why should I have to do so much more because they are not doing their part? This apparent unfairness leads Liam Murphy to the view that individual agents are not obliged to do more than they would have to do under conditions of full compliance. ${ }^{84} \mathrm{He}$ writes: "a principle of beneficence should not increase its demands on agents as expected compliance with the principle by other agents decreases." 85

Murphy has surely identified something important here. It would be unfair to make those who are willing to do their part shoulder all the burdens of the rescues that should be collectively provided for. However, the agents on whom obligations of beneficence fall are not the only parties who are treated unfairly. As Michael Ridge points out, if we accept Murphy's view, then all the burden of noncompliance falls on the people

${ }^{84}$ Liam Murphy, Moral Demands in Nonideal Theory (Oxford: Oxford University Press, 200o). Note that Murphy does express some uncertainty about following through with this principle to the case of extreme poverty ("The Demands of Beneficence," Philosophy \& Public Affairs 22 [1993]: 267-292, at 276-277).

${ }^{85}$ This is what Murphy labels the "compliance condition" (ibid., p. 278). 
who are in need of our help. ${ }^{86}$ Moreover, these people are the people who are already most unfortunate! That seems even more unfair. Instead, Ridge suggests, in cases where not everyone does what they should, we need to distribute fairly the burdens of noncompliance. In cases where some of the parties involved are much better off than others, fairness will demand that more of the burdens of noncompliance should fall on the better-off party.

To make this idea more concrete, suppose that if everyone did what they should, then each affluent person in the United Kingdom would have a duty to contribute $£ 2,000$ on the basis of beneficence as a contribution to alleviating the worst effects of global poverty. Not everyone does this, and so many people in the world suffer from malnutrition and preventable diseases of poverty who otherwise would not. It would be unfair to ask all the people in the United Kingdom who are willing to do their part to contribute substantially more in order to make up the gap. On the other hand, it would be unfair to ask people living in extreme poverty to continue to suffer from easily preventable illness so as to save affluent Brits money. There will be unfairness either way for which we can blame the people who are not contributing anything. But between affluent Brits and the global poor, it is surely the former who should shoulder most of the burden of this noncompliance. On the assumption that there are sufficient opportunities for affluent Brits to continue to give more money to effectively alleviate extreme poverty, those who give should be doing so up to the point where it has a nontrivial impact on their household's wellbeing. For the typical affluent British household, we would expect this to be thousands of pounds more than they would have to give under full compliance.

Finally, consider the implications of our discussion for clinicians in a wealthy country like the United States where I I.I percent of the adult population under age sixty-five is uninsured ${ }^{87}$ and 23 percent are considered underinsured. ${ }^{88}$ These people either cannot access needed care or face

86 "Fairness and Non-Compliance," in Brian Feltham and John Cottingham (eds.), Partiality and Impartiality (Oxford: Oxford University Press, 2010): 194-222.

87 These 2018 data come from Centers for Disease Control and Prevention, "Health Insurance Coverage" (available at www.cdc.gov/nchs/fastats/health-insurance.htm; accessed August I 8,2020$)$.

88 "Underinsured" is defined by the Commonwealth Fund as someone with health insurance whose out-of-pocket costs, excluding premiums, are io percent or more of household income ( 5 percent if poor), or whose deductible is 5 percent or more of household income (Sara Collins, Petra Rasmussen, Sophie Beutel, and Michelle Doty, "The Problem of Underinsurance and How Rising Deductibles Will Make It Worse. The Commonwealth Fund [2015]"; available at www.commonwealthfund.org/publications/issue-briefs/20 I $/ \mathrm{may} /$ problem-of-underinsurance). 
large out-of-pocket expenditures and medical debt when they do. As we argue in the following section, the health care system in the United States is a long way from meeting the demands of distributive justice. What obligations do clinicians, such as physicians, have to provide care to such patients?

We maintain that these obligations are quite substantial. The need is great, physicians have the skills to meet the need, and many could do so without great personal hardship. Thus, it is plausible that they have perfect duties of beneficence to provide a substantial amount of care without charge or at a minimal cost. For example, a physician who has a private practice might charge patients on the basis of a sliding scale of fees proportionate to patients' ability to pay; alternatively, they might charge the same amount for most patients while setting aside a number of appointments per week in which they serve indigent or uninsured patients for free. ${ }^{89}$

Now, it is true that if the health care system were reformed, then individual physicians would not have to volunteer their time to treat poorer patients. It is also true that if all physicians volunteered time, then each would have only a small contribution to make. But neither of these conditions is met in the actual world. Each individual physician therefore has the duty to do considerably more than they ideally would to provide care for patients who would otherwise go without.

Note, finally, that we have been discussing only physicians' general duty to provide care to those in need - that is, a duty grounded in the physicians' ability to provide assistance at relatively low cost to themselves. One might think that physicians have further, special duties to provide care to the needy that are grounded in the role morality of physicians. It is undisputed that physicians have some role-based duties to their existing patients. ${ }^{90}$ In addition to such duties as truth-telling and confidentiality, which are derivable from respect for patient autonomy, physicians have

${ }^{89}$ Strictly speaking, physicians would not have to fulfill their duties of beneficence by providing medical care to those who cannot otherwise access it. They could, instead, practice in a lucrative specialty and donate a substantial proportion of their earnings.

90 A classic statement of physicians' duties that reflected traditional paternalism toward patients is the Hippocratic Oath (reprinted in David DeGrazia, Thomas Mappes, and Jeffrey Brand-Ballard [eds.], Biomedical Ethics, 7th ed. [New York: McGraw-Hill, 20II], 69-70). For more up-to-date statements, see the American Medical Association Council on Ethical and Judicial Affairs, "Fundamental Elements of the Patient-Physician Relationship," in Code of Medical Ethics: Current Opinions with Annotations (2008-2009 edition); and Edmund Pellegrino, "The Virtuous Physician and the Ends of Medicine," in Earl Shelp (ed.), Virtue and Medicine (Dordrecht: Reidel, I985), $248-253$. 
obligations to provide their patients excellent medical care and actively support their capacity to make autonomous medical decisions, which are role-based duties of beneficence. One might think that such duties to one's existing patients do not exhaust the content of the physician's role. A more expansive view of the role morality of physicians - and other health care practitioners - might include wider duties to improve health care provision within their society or abroad. ${ }^{9 \mathrm{I}}$

\subsection{Domestic Justice: The Right to Access Health Care}

In nearly all HICs, all citizens have access to a wide range of medical services as a matter of government policy. The United States is one important exception where, as just noted, there are still millions of people who lack, or have inadequate, health insurance. The situation in low- and middle-income countries (LMICs) varies tremendously. For example, Thailand has massively expanded its publicly funded health insurance schemes over the last two decades to cover millions more people and to cover more services; while total health expenditure grew from 3.I percent of GDP in 2000 to 3.7 percent of GDP in 2017 , the proportion that is public expenditure nearly doubled - to 2.9 percent of GDP - and private expenditure nearly halved..$^{92}$ By contrast, in India, 70 percent of health care expenditure is still private and nearly 90 percent of that is paid out of pocket. Disparities in care in India are vast: around 40 percent of women reported giving birth in a health facility for their most recent birth in 2005-2006, and women in the highest wealth quintile were six times more likely to do so than women in the lowest quintile. ${ }^{93}$ Nonetheless, with the encouragement of the $\mathrm{WHO}$, many countries are pushing to provide more health care coverage to more of their population. ${ }^{94}$

Many people regard access to affordable health care as a right. ${ }^{95} \mathrm{~A}$ right to health - and correlatively to health care - is enshrined in the

9I See, e.g., Project of the ABIM Foundation, ACP-ASIM Foundation, and European Federation of Internal Medicine, "Medical Professionalism in the New Millennium," Annals of Internal Medicine I 36 (2002): 243-246.

${ }^{22}$ The World Bank, World Bank Open Data (available at https://data.worldbank.org; accessed August I 8, 2020).

93 Yarlini Balarajan, Selvaraj Selvaraj, and S. V. Subramanian, "Health Care and Equity in India," The Lancet 377 (201 I): 505-515.

94 World Health Organization, "Universal Health Coverage" (available at www.who.int/health-topics/ universal-health-coverage; accessed August I 8, 2020).

95 According to WHO, in this context "affordable" means that there is "a system for financing health services so people do not suffer financial hardship when using them” (World Health Organization, 
constitution of many states. ${ }^{96}$ It is recognized in multiple human rights documents, including the International Covenant on Economic, Social and Cultural Rights, the realization of which includes "creation of conditions which would assure to all medical service and medical attention in the event of sickness." ${ }^{\text {97 }}$ And the Sustainable Development Goals (SDGs) that replaced the Millennium Developmental Goals include among the targets for Goal 3: "Achieve universal health coverage, including financial risk protection, access to quality essential health-care services and access to safe, effective, quality and affordable essential medicines and vaccines for all." 98

Here, we argue that individuals have a right to affordable health care by showing how it follows from the liberal egalitarianism we have defended. ${ }^{99}$ We also show that the right will have limits: it does not require that all potentially beneficial services be provided for free, nor that all such services must be covered.

The first step is to note that diminished health can have an enormous negative impact on an individual's well-being. Indeed, on most measures, the severity of a disease is a function of its impact on patients' quality of life and reduction in their lifespan. ${ }^{\text {Ioo }}$ Daniels takes the negative effects of illhealth on the range of opportunities open to individuals to be so significant that universal access to health care is necessary for equality of opportunity. ${ }^{\text {IOI }}$ We do not need to go so far in order to accept that health and so access to health care are frequently very important for a flourishing life. In large part, the impact of disease on well-being is unchosen: individuals do not usually become ill as a result of informed, voluntary decisions. (Possible exceptions are the source of much debate over personal responsibility for health.) Hence, it is presumptively unjust for individuals to bear the costs of averting or treating ill health and premature death.

\footnotetext{
"Questions and Answers on Universal Health Coverage"; available at www.who.int/healthsystems/ topics/financing/uhc_qa/en/; accessed August I 8, 2020).

96 Eleanor Kinney and Brian Clark, "Provisions for Health and Health Care in the Constitutions of the Countries of the World," Cornell International Law Journal 37 (2004): 285-355.

97 United Nations, International Covenant on Economic, Social, and Cultural Rights, Article I 2.

98 United Nations, Sustainable Development Goals (available at www.un.org/sustainabledevelopment/ health/; accessed August I 8, 2020).

99 For more discussion and alternative arguments for a right to health care, see Norman Daniels, in Edward Zalta (ed.), "Justice and Access to Health Care," Stanford Encyclopedia of Philosophy (Winter 20I7 edition; available at https://plato.stanford.edu/entries/justice-healthcareaccess/).

זо This is true, for example, of both quality-adjusted life-years (QALYs) and disability-adjusted lifeyears (DALYs).

го Norman Daniels, Just Health Care (New York: Cambridge University Press, 1985).
} 
Second, health care has some distinctive features that make it unlike some other goods - such as nutritious food or potable water - that are also essential prerequisites to human flourishing. Unlike food and water, individual needs for health care are often hard to predict and can be extremely expensive. For some high-cost, high-value procedures - for example, ICU treatment for victims of traffic accidents - it would be impossible to ensure that everyone had the money to pay out of pocket for needed care. The uncertainty and variability in need for health care, along with its potentially high cost, means that some sort of risk pooling is necessary. One might then think that it would be sufficient for the state to ensure that everyone had the money to buy insurance against excessive health costs. But here the partial predictability of health care needs becomes a problem. Some people, such as those with diagnosed chronic conditions that require ongoing treatment, will definitely have high health care costs. Others - such as young, currently healthy individuals - know that they are much less likely to need care in the short term. A free market in health insurance therefore leads to adverse selection, as those who know themselves more likely to need health care are more likely to buy insurance than those who expect to use less health care. Insurers must then increase insurance premiums to cover the increase in expected per capita use of health care. Increased premiums price more of the healthier people out of the market, further driving up per capita costs, and so on. Affordable health insurance therefore requires some way to prevent adverse selection. On a national scale, this requires state intervention to ensure that everyone has access to health care.

Liberal egalitarianism entails a right to access affordable health care. It does not entail that all services must be supplied for free, only that costs involved are ones that people can afford without risk of impoverishment. Nor does it entail that all medically beneficial services must be provided to those who would benefit from them. The right to health care derives from the same foundation as other justice-based claims to resources. Since the total resources available are limited, there will inevitably be trade-offs, as we described above. Those may involve trade-offs between health care and other important goods, as well as trade-offs among health care services that would benefit populations with different health needs.

Last, though liberal egalitarianism entails a right to access affordable health care, it does not tell us what mechanism should be used in order to fulfill this right. Some HICs, such as the United Kingdom, provide most care through a public health care system. Others have substantial private provision, but the government is the main payer, as in Canada. Still others 
have multiple payers, but mandatory health insurance and premiums that reflect ability to pay, as in Germany. Our view of justice does not favor one of these institutional structures over another. Any of them can implement a right to health care access. The current US approach - with its gaps in insurance coverage and high out-of-pocket costs even for individuals who have insurance - clearly cannot.

\subsection{Global Injustice: Intellectual Property Laws and Pharmaceuticals}

Of the approximately $\$ 240$ billion spent each year on medical research, ${ }^{\text {102 }}$ about three-fifths is spent by for-profit companies. The vast majority of research supported by for-profit companies (henceforth "companies") is aimed at developing and testing new drugs and devices that they hope to market. The development of new medical technologies is expensive. In order to receive marketing authorization - from, say, Health Canada, the US Food and Drug Administration, or the European Medicines Agency a company must demonstrate the safety and efficacy of the new drug or device. This requires multiple scientific studies in humans and nonhuman animals. Most promising drugs and devices fail during the testing process. The revenue from successful products must therefore make up for the costs of all this research. The primary function of patent law is to incentivize companies to develop new drugs and devices, despite the substantial upfront costs of doing so. ${ }^{\text {IO3 }}$

A patent on an invention grants its holder exclusive property rights over the invention for an extended period of time. For pharmaceutical products - we focus on drugs here for ease of writing, but the same points apply to devices - the resulting monopoly allows companies to set prices far greater than the marginal cost of manufacture. As a result, brand-name drugs under patent are typically much more expensive than those whose patent has expired and which therefore face competition from the manufacturers of generic copies. In 1994, the WTO adopted the Agreement on Trade-Related Aspects of Intellectual Property Rights (TRIPS agreement). This legally binding agreement requires all WTO members to provide

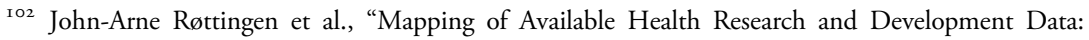
What's There, What's Missing, and What Role Is There for a Global Observatory?," Lancet 382 (2013): I 286-I307.

I03 This is the commonly accepted instrumental justification for intellectual property. For discussion of alternative justifications, see Justin Hughes, “The Philosophy of Intellectual Property,” Georgetown Law Journal 77 (I988): 287-366. 
protections for intellectual property rights, including patents on inventions that extend for at least twenty years. ${ }^{\text {I04 }}$

The global intellectual property regime has two especially pernicious effects on poorer patients. First, monopoly pricing means that many pharmaceutical products in LMICs are priced out of the reach of the majority of the patients who could benefit from them. For example, most patients in India are unable to afford highly effective treatments for breast cancer and leukemia. ${ }^{\text {IO5 }}$ Second, because revenue from inventions is directly tied to sales, the international patent regime encourages companies to focus on developing patentable technologies for conditions that affect richer patient groups. This means that research into diseases that predominantly affect the poor - including many infectious tropical diseases - is woefully underfunded relative to the disease burden. ${ }^{\text {Io6 }}$

Is the lack of affordable drugs for non-rich patients in LMICs unjust? Two argumentative strategies have been proposed to show that it is.

The first argumentative strategy, championed by Thomas Pogge, is to contend that the international patent regime is unjust because it harms patients. ${ }^{107}$ Since all political views accept that we should not harm innocent others without their consent (or some weighty countervailing consideration), if Pogge is correct, then the international patent regime is illegitimate. ${ }^{\text {I08 }}$ Pogge's view relies on several key normative and empirical premises.

${ }^{104}$ Developing countries were granted a transition period until 2005. "Least developed countries" have had this transition period for pharmaceutical products extended until at least 2033 (www.wto .org/english/news_e/newsis_e/trip_o6novis_e.htm). The Doha Declaration on the TRIPS Agreement and Public Health in 200I clarified that the TRIPS agreement "should be interpreted and implemented in a manner supportive of WTO Members' right to protect public health and, in particular, to promote access to medicines for all" (www.wto.org/english/thewto_el minist_e/mino I_e/mindecl_trips_e.htm). Use of the exceptions noted in the Doha Declaration has been limited and fiercely contested by HIC governments and pharmaceutical companies.

ros Daniel Goldstein et al., "A Global Comparison of the Cost of Patented Cancer Drugs in Relation to Global Differences in Wealth," Oncotarget 8 (2017): 71 548-7I 555.

го6 Nick Chapman et al., "Neglected Disease Research and Development: Reaching New Heights," G-FINDER Report (20I8) (available at www.indiaenvironmentportal.org.in/files/file/G-FINDER_ Full_report.pdf).

107 Thomas Pogge, “Are We Violating the Human Rights of the World's Poor?,” Yale Human Rights o Development Law Journal I 4 (20I I): I-33. Though there has been some debate about whether the global institutional order as a whole harms the global poor, we find the arguments regarding the harmfulness of the international patent regime, in particular, compelling. For some critical discussion, see Mathias Risse, "How Does the Global Order Harm the Poor?," Philosophy \& Public Affairs 33 (2005): 349-376.

108 Might the harms caused by the international patent regime be the result of a fair competition and so not wrong the victims (Chapter 4 )? The harms to companies whose products do not succeed plausibly do not involve wrong-doing for this reason. The harms we are discussing here, though, are harms to patients who are not part of the competition at all, so we answer our question negatively. 
One key premise, that the putative victims of harm did not consent to it, is highly plausible: though the governments of all parties to the TRIPS agreement did agree to it, it is implausible that this agreement constitutes the consent of patients affected by the agreement. For one, membership of the WTO is not possible without accepting TRIPS, and the costs to a country's economy of not being in the WTO are very high. Thus, the voluntariness of a particular government's decision to implement its TRIPS obligations is questionable. Perhaps more importantly, individuals in WTO countries are very unlikely to have known about TRIPS before its implementation, unlikely to have anticipated that their representatives would be acceding to foreign powers restricting their access to medicines, and (in many cases) unlikely to have had a real say in who those representatives were.

A second premise of Pogge's harm argument is that the international patent regime causes harm. This requires showing that patients are worse off than they otherwise would be. ${ }^{109}$ If we hold fixed the state of medical knowledge, this claim seems highly plausible. We argued in the previous section that persons have a right to health care, which will include a right to access important medicines. High prices for medicines can interfere with the realization of that right. (Even though we construed the right to health care as a right of individuals against their own government or society, the high drug prices permitted by the current international regime interfere with a state's ability to meet the obligations entailed by this right.) Moreover, up until recently, many countries had weaker intellectual property laws, which allowed for the production of generic medications much earlier than the current system. For example, until 2005 India allowed patents only on processes, not products, and for much shorter periods than the twenty years TRIPS prescribes. ${ }^{\text {IIO }}$ As a result, India developed a huge generic medicines industry that supplied domestic and international markets. The patent regime that the TRIPS agreement brought in therefore appears to be reducing access to needed medicines.

One might respond that this argument ignores the gains in terms of medical innovation that result from stricter patent laws. Certainly, patients now are worse off with respect to existing medicines than if we abandoned patents, but doing so would cause future patients to miss out on preventive and treatment interventions for diseases that we cannot currently address. Thus, the argument that the current international intellectual property

ro9 See Chapter 4 for a discussion of how to conceptualize harm.

I 10 The product/process distinction meant that competitors could manufacture identical drugs if they could find an alternative process by which to make them. 
regime harms patients must show that there are alternatives to the current system that would be as good or better for future patients. We turn to this point shortly.

The second argumentative strategy for showing that lack of affordable drugs in LMICs is unjust derives from the cosmopolitan view that we defended earlier. Cosmopolitans also have reason to criticize the international patent regime. It benefits some of the best-off people in the world, such as the shareholders of pharmaceutical companies. Moreover, the benefits it provides them - in terms of actual welfare gains - are very small, since they are already materially well-off. Their gains come at the expense of poor patients who would otherwise have access to medical interventions that would provide substantial health benefits and sometimes save their lives. No matter how we treat the trade-off between gains to the disadvantaged and maximizing total benefits, the current system of patent protection looks unjust.

This cosmopolitan argument, like the harm argument, relies on the claim that there are alternatives to the present system. Such alternatives should be ones that would still lead to the development of beneficial medical interventions, but make drugs more affordable, more attuned to global health needs, or both. The literature on drug development suggests multiple alternative models. ${ }^{\text {II }}$

Some alternatives to the intellectual property system would involve minimal deviation from the current system. For example, the prices of existing medications could be dramatically reduced if individual countries made much greater use of compulsory licensing. A compulsory license involves a government permitting manufacture of generic versions of a drug that is still under patent provided that the manufacturers pay the patent holder a reasonable fee. Though permitted under the TRIPS agreement, the use of compulsory licenses in the context of pharmaceutical patents is strongly discouraged by richer countries and has been subject to legal challenges where used. ${ }^{\text {II } 2}$ One might argue that extensive use of compulsory licenses by LMICs would disincentivize research by reducing the expected profits for patent-holders. This seems unlikely: the vast

II For a number of examples, see Thomas Pogge, Matthew Rimmer and Kim Rubenstein (eds.), Incentives for Global Public Health (Cambridge: Cambridge University Press, 2010).

I 2 For example, Thailand has issued a number of compulsory licenses for expensive drugs, including second-line antiretrovirals for HIV/AIDS. This led to objections from the European Union Commissioner for External Trade, the United States Trade Representative putting Thailand on its "Special 30I" Priority Watch List, and Abbott Laboratories, one of the patent holders, temporarily refusing to register new drugs in Thailand. See Jonathan Burton-Macleod, "Tipping Point: Thai Compulsory Licences Redefine Essential Medicines Debate," in Pogge, Rimmer, and Rubenstein, Incentives for Public Global Health, 406-424. 
majority of the patients who can afford expensive patented drugs are living in HICs, and so allowing patients in LMICs to obtain cheaper versions of them would not substantially reduce sales. ${ }^{\mathrm{II} 3}$

Other proposals would involve bigger changes to the current system for drug development. Some writers have suggested that prizes could provide the necessary incentive for private actors to innovate. ${ }^{\text {II } 4}$ Thus, for example, the United Kingdom's recent Longitude Prize offers $\mathfrak{E}_{\text {IO }}$ million for the creation of "a cheap, accurate, rapid and easy-to-use point of care test kit for bacterial infections," as a tool to combat antibiotic resistance. ${ }^{\text {II }}$ Pogge proposed a related scheme - the Health Impact Fund - whereby companies could take out an alternative patent which would mean they were reimbursed proportional to the actual effect of a new drug on the burden of disease. ${ }^{\text {II }}$ Finally, a great deal of health research is already directly publicly funded, for example, via competitively allocated grants to academic researchers. ${ }^{17}$ The development of new interventions for diseases of poverty already relies heavily on such funding sources. ${ }^{I 8}$ One might then imagine expanding public support for developing new health technologies that could be privately manufactured without patent protection or with licenses conditional on affordable pricing.

The current international intellectual property regime is unjust. It substantially reduces access to important medicines for billions of people for benefits that could be better realized in other ways. Governments, especially those of richer countries, have a duty to permit the manufacture of affordable existing medicines and to adopt alternative means to incentivize the development of new ones.

\footnotetext{
${ }^{113}$ Jens Plahte, "Tiered Pricing of Vaccines: A Win-Win-Win Situation, not a Subsidy," Lancet Infectious Diseases 5 (2005): 58-63.

${ }^{I 1}$ William Fisher and Talha Syed, "A Prize System as a Partial Solution to the Health Crisis in the Developing World," in Pogge, Rimmer, and Rubenstein, Incentives for Public Global Health, I 8 I-208.

II Nesta, "Longitude Prize" (https://longitudeprize.org; accessed September 28, 2020).

${ }^{116}$ Health Impact Fund (http://healthimpactfund.org; accessed September 28, 2020).

${ }^{117}$ Røttingen et al. estimated 30 percent of health research funding is from government entities ("Mapping of Available Health Research and Development Data").

${ }^{118}$ For example, BRV-PV (or Rotasil) is a new oral rotavirus vaccine that is expected to be much cheaper than existing vaccines. Its development was supported by PATH (a nonprofit funded largely by governments and foundations) using BRV strains developed by the US National Institutes of Health, and it is manufactured by the Serum Institute of India (a private company). See Prasad Kulkarni et al., "A Randomized Phase III Clinical Trial to Assess the Efficacy of a Bovine-Human Reassortant Pentavalent Rotavirus Vaccine in Indian Infants," Vaccine 35 (2017): 6228-6237.
} 